\title{
FABRICATION AND TESTING OF MICROMACHINED SILICON CARBIDE AND NICKEL FUEL ATOMIZERS FOR GAS TURBINE ENGINES
}

\author{
N. Rajan, M. Mehregany, C. A. Zorman, and T. P. Kicher* \\ Microfabrication Laboratory \\ Dept. of Electrical Engineering and Applied Physics \\ *Dept. of Mechanical and Aerospace Engineering \\ Case Western Reserve University \\ Cleveland, $\mathrm{OH} 44106$
}

\begin{abstract}
Bulk micromachining of high-temperature materials is an enabling technology for the application of MEMS devices in high-temperature environments. This paper presents a novel molding method for fabricating silicon carbide $(\mathrm{SiC})$ fuel atomizers for gas turbine engines. The devices are compared to similar nickel (Ni) atomizers fabricated using the LIGA process. Performance and erosion tests demonstrate that both types of atomizers are able to perform well at pressures in excess of $2500 \mathrm{kPa}$, with the $\mathrm{SiC}$ devices exhibiting a higher erosion resistance. The results demonstrate a significant improvement over similar silicon ( $\mathrm{Si}$ ) devices, which are limited in operation to pressures below $1400 \mathrm{kPa}$ and are comparatively not resistant to erosive wear.
\end{abstract}

\section{INTRODUCTION}

The fabrication of micromachined fuel atomizers from high-temperature materials is a follow-on to our earlier research on $\mathrm{Si}$ micromachined atomizers. The $\mathrm{Si}$ devices afforded a high level of dimensional precision, which is lacking in both conventionally-machined and macrolaminate atomizers [1,2]. However, under extremely erosive operational conditions, the $\mathrm{Si}$ atomizers suffered significant wear. While the development of hard coatings for these $\mathrm{Si}$ devices provided a solution for improving the wear resistance [1], there remains a need for fabricating the complete atomizer from a material with high-temperature stability.

The fabrication of MEMS devices from hightemperature materials has been hampered by the lack of processing technologies to micromachine high-performance ceramics, like SiC. While RIE techniques have been developed to fabricate surface micromachined structures from SiC thin films [3], more complex three dimensional structures have not yet been realized. SiC's excellent chemical stability/inertness significantly limits pattern delineation, depth and accuracy when utilizing etch processes. Processes like LIGA provide the opportunity to fabricate micromachined devices from $\mathrm{Ni}$, harnessing a material already used in the aerospace industry for its hightemperature characteristics and wear resistance in alloyed form. However, LIGA is not widely available and is often costly, driving the search for viable fabrication alternatives.

A novel processing approach is introduced in this paper to fabricate bulk micromachined MEMS devices, such as the atomizer, from materials other than $\mathrm{Si}$. The approach uses Si molds fabricated by deep reactive ion etching (DRIE) and provides for controlled depth variations in the thickness direction. SiC atomizers are fabricated by high-rate deposition of $\mathrm{SiC}$ into these molds. While fabrication of $\mathrm{Ni}$ atomizers using this molding approach is currently in progress, $\mathrm{Ni}$ atomizers were also fabricated in two layers using the LIGA process, with the two layers of the device being assembled after release. The performance of the SiC and $\mathrm{Ni}$ (LIGA) atomizers are compared with one another and with $\mathrm{Si}$ atomizers.

\section{FABRICATION}

The Si molds were fabricated out of a $500 \mu \mathrm{m}$-thick (100) Si substrate using DRIE. The process flow is shown in Fig. 1. The novelty of the process lies in the patterning of both the first and second etch step masks before any DRIE etching, overcoming the problem of patterning a substrate for a second etch after the first bulk etch is completed.

The two mask materials used to fabricate the mold were thermal oxide and thick photoresist (Shipley AZ 4620). The process begins with a $1 \mu \mathrm{m}$ growth of silicon dioxide on the substrate. The oxide was patterned using a standard lithographic process for the first etch. This pattern defined the etch mask for the deepest parts of the mold. The next step required the patterning of the thick photoresist on top of the patterned oxide layer. Notice from the process flow that the resist necessarily exposes more of the underlying substrate than the oxide. This allowed the exposed surfaces during the first etch to continue being etched during the second etch step.

The first etch was then performed to a depth of 275 $\mu \mathrm{m}$, defining the depth of the annulus, inlet slots, and swirl chamber. After the first etch was completed, the oxide layer was removed using buffered HF, exposing the areas for the second etch defined by the thick photoresist. The second etch was then performed to remove an additional $125 \mu \mathrm{m}$ of $\mathrm{Si}$, resulting in a maximum mold depth of $400 \mu \mathrm{m}$, and a minimum mold depth of $125 \mu \mathrm{m}$, with the unetched center 


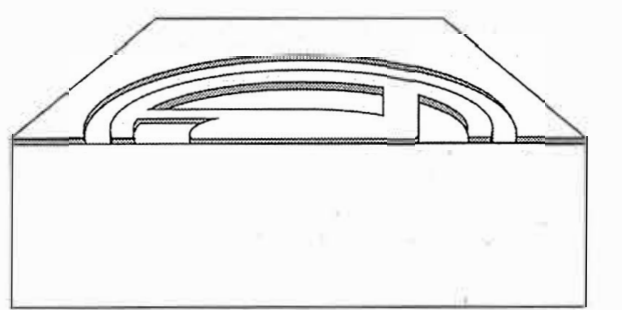

Step 1: Grow oxide and pattern

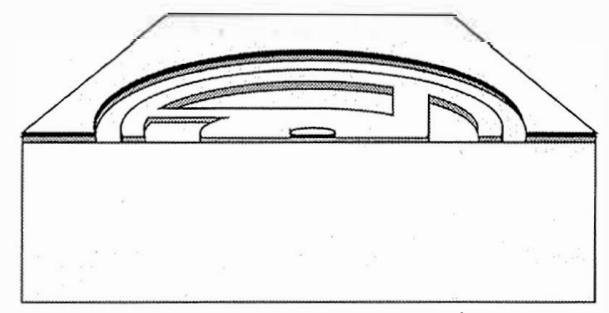

Step 2: Spin on thick resist and pattern

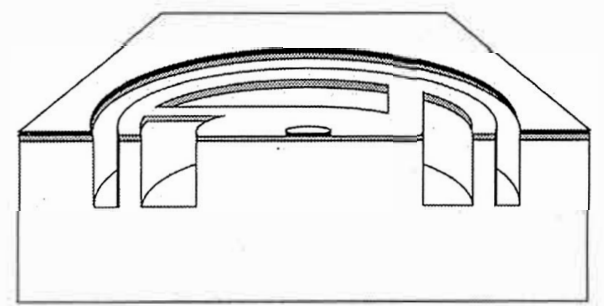

Step 3: First $275 \mu \mathrm{m}$ deep DRIE etch

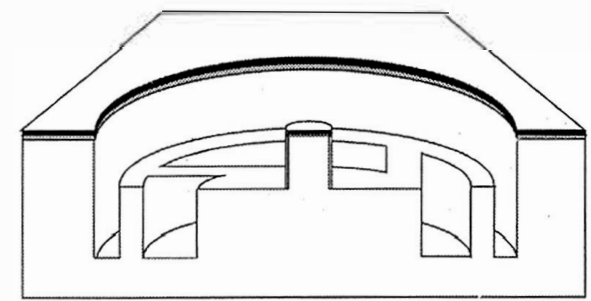

Step 4: Remove oxide and second DRIE etch for an additional $125 \mu \mathrm{m}$

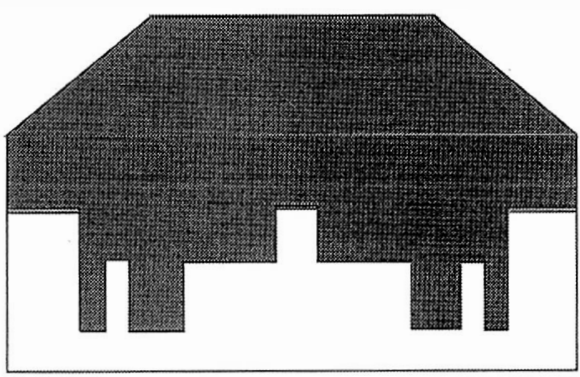

Step 5: Deposit $400 \mu \mathrm{m}$ of $\mathrm{SiC}$

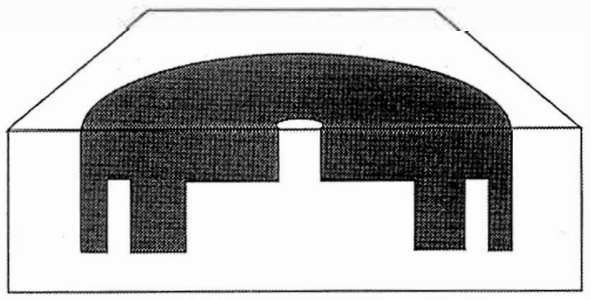

Step 6: Polish excess $\mathrm{SiC}$ and release

Fig 1: Process flow for SiC atomizer micröfabrication.

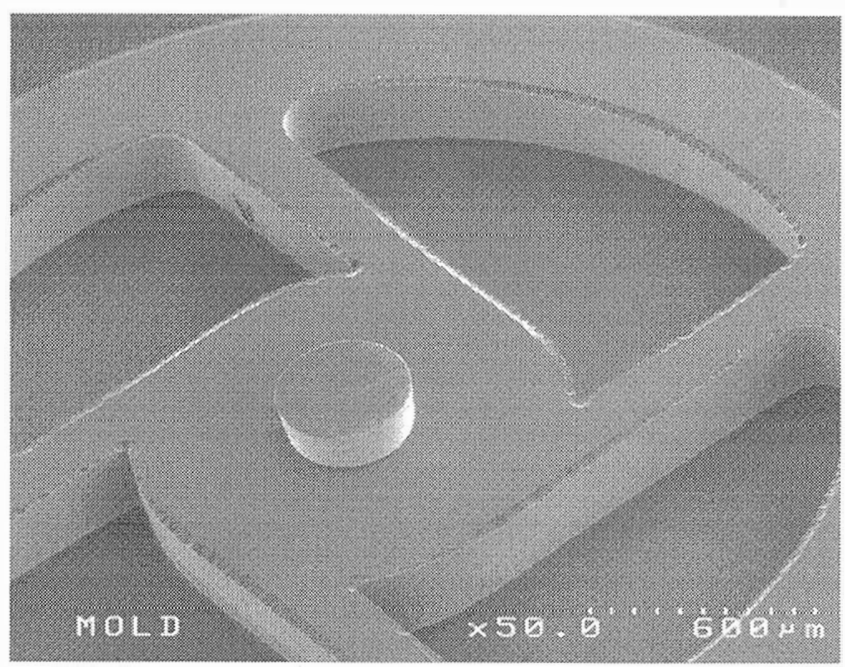

Fig. 2: SEM photo of the Si mold prior to SiC deposition.

post providing the molding for the exit orifice through hole. The final step for the mold preparation was the removal of the resist using piranha. An SEM micrograph of the mold is shown in Fig. 2.

The $\mathrm{SiC}$ mold filler was deposited in a high-rate $\mathrm{SiC}$ CVD reactor to a thickness of $400 \mu \mathrm{m}$ using methyltrichlorosilane (MTS) at a temperature of $1200^{\circ} \mathrm{C}$. As the deposition occurred both in the mold and on the field areas, mechanical polishing was required to remove the excess $\mathrm{SiC}$. This was achieved using a two step process. The first step was a lapping phase for the rapid removal of $\mathrm{SiC}$ using a $15 \mu \mathrm{m}$ polycrystalline diamond suspension on a cast iron polishing plate. The second step utilized a $1 \mu \mathrm{m}$ polycrystalline diamond suspension to slow the removal of the $\mathrm{SiC}$, as well as to reduce its surface roughness. Once the $\mathrm{SiC}$ was completely removed from the field area, the device was released using a $\mathrm{KOH}$ solution at $55^{\circ} \mathrm{C}$. It should be noted that the mold filler can be any material that can sustain high deposition rates on a Si substrate, and work is currently under way to fabricate $\mathrm{Ni}$ (i.e. in alloyed form) atomizers using the Si molds and electroless plating.

The LIGA devices were fabricated using the MCNC LIGAMUMPs thick nickel $(200 \mu \mathrm{m})$ process. For this process, the atomizer was designed in two halves, with the first containing the channel, annulus, and swirl chamber floors, as well as the exit orifice, and the second containing the structures used to define the channel, annulus, and swirl chamber walls. The mold was made from PMMA and Ni electroplating was used to deposit the atomizer structures.

\section{EXPERIMENTAL PROCEDURE}

The micromolded atomizers were tested for standard performance characteristics and erosion resistance. The tests were performed at the Parker Hannifin Gas Turbine Fuel Systems Division laboratory (Mentor, $\mathrm{OH}$ ) using an evaluation format established at Parker for the testing of prototype atomizers. The performance measurements were 
accomplished using a Parker A-3000 test stand. The spray quality was qualitatively evaluated and the fuel flow in $\mathrm{lbs} / \mathrm{hr}$ $(\mathrm{PPH})$ was measured for both $\mathrm{SiC}$ and $\mathrm{Ni}$ atomizers. The erosion test was designed to exaggerate real-world operating conditions by flowing an erosive mixture several orders of magnitude more aggressive than jet fuel. The efosive mixture was composed of variously sized black and red iron oxide particles, Arizona road dust, and salt water in MIL-C7024 Type II test fluid. The contaminated fluid was fed through the atomizers at a pressure of $2660 \mathrm{kPa}$ for a duration of 4.5 hours.

\section{RESULTS AND DISCUSSION}

The $\mathrm{Ni}$ atomizers were successfully fabricated in two parts using the MCNC LIGAMUMPs process. SEM micrographs of the two parts of the $\mathrm{Ni}$ devices are shown in Fig. 3. The $\mathrm{SiC}$ devices were also successfully fabricated using the $\mathrm{Si}$ micromolding process. An SEM micrograph of the $\mathrm{SiC}$ device is shown in Fig. 4. Examination of the $\mathrm{SiC}$ atomizer surfaces reveals $\mathrm{SiC}$ protrusions from the exit orifice and at various locations in the swirl chamber. These outgrowths are generated during the SiC CVD process, not during mold fabrication. The SEM micrograph in Fig. 2 shows the surfaces of a typical $\mathrm{Si}$ mold to be smooth and featureless. It has been observed that depositing $\mathrm{SiC}$ using MTS as the deposition gas results in void formation on the Si substrate at low deposition rates [4]. It is hypothesized that the irregular $\mathrm{SiC}$ device morphology is a consequence of this phenomenon.

The flow performance of the $\mathrm{SiC}$ and $\mathrm{Ni}$ atomizers were compared to Si micromachined atomizers of like design [1]. The Si micromachined atomizers were used as a reference for evaluating the $\mathrm{SiC}$ and $\mathrm{Ni}$ devices. Despite the morphological differences in the flow surfaces, the results showed that all devices had comparable flow numbers and comparable spray angles, with the $\mathrm{Ni}$ atomizers having slightly lower flow rates. The average flow rate for the $\mathrm{SiC}$ atomizers was $9 \mathrm{PPH}$, and the $\mathrm{Ni}$ atomizers $7 \mathrm{PPH}$, at an operating pressure of $660 \mathrm{kPa}$. Similar $\mathrm{Si}$ atomizers averaged $10 \mathrm{PPH}$ at the same pressure. In addition, both the $\mathrm{SiC}$ and $\mathrm{Ni}$ devices could be operated continuously at much higher pressures than the Si devices, spraying consistently at pressures in excess of $2000 \mathrm{kPa}$, even though the SiC atomizer swirl chamber floor was generally half the thickness of comparable Si devices.

The erosion tests showed that the $\mathrm{SiC}$ devices performed better than the Ni devices, and both were superior to the $\mathrm{Si}$ atomizers in [1]. This is demonstrated clearly by the SEM photos of Figs. 5 and 6. Figure 5 is a set of preand post-erosion SEM micrographs of the $\mathrm{Ni}$ atomizers, with the inlay providing a close-up of the exit orifice edge. It was determined that this was the area most susceptible to erosive wear [1]. Figure 5 shows that the relative softness of $\mathrm{Ni}$ compared to $\mathrm{SiC}$ has led to heavy gouge patterns at the orifice edge, with significant scouring on the swirl chamber floor close to the exit orifice. This is attributed to the relatively high purity of the $\mathrm{Ni}$ in the electroplated form. In contrast, the $\mathrm{SiC}$ atomizers (Fig. 6) show no discernible evidence of wear.

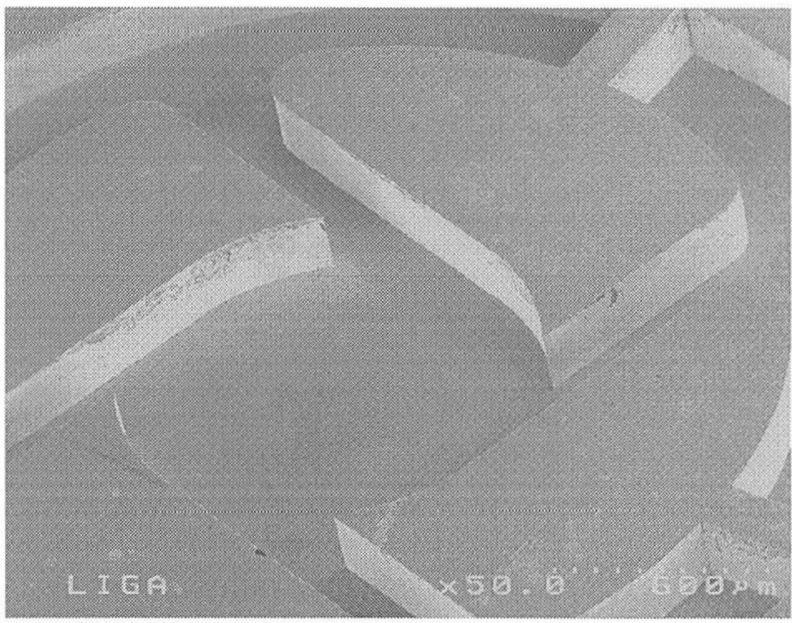

(a)

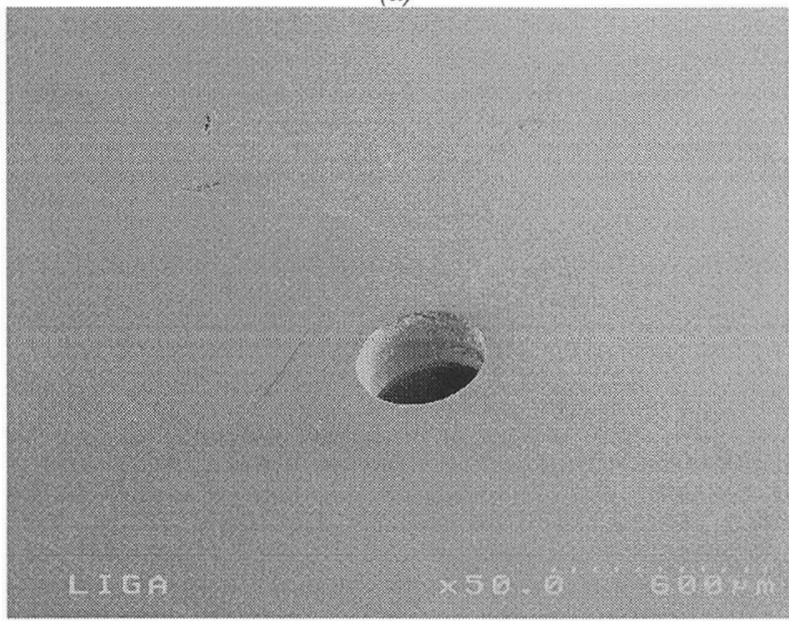

(b)

Fig. 3: SEM photos of the two parts of a Ni atomizer: (a) One half defining the annulus, inlet slot, and swirl chamber walls; and (b) the other half containing the exit orifice (SEM scales identical to that in Fig. 4).

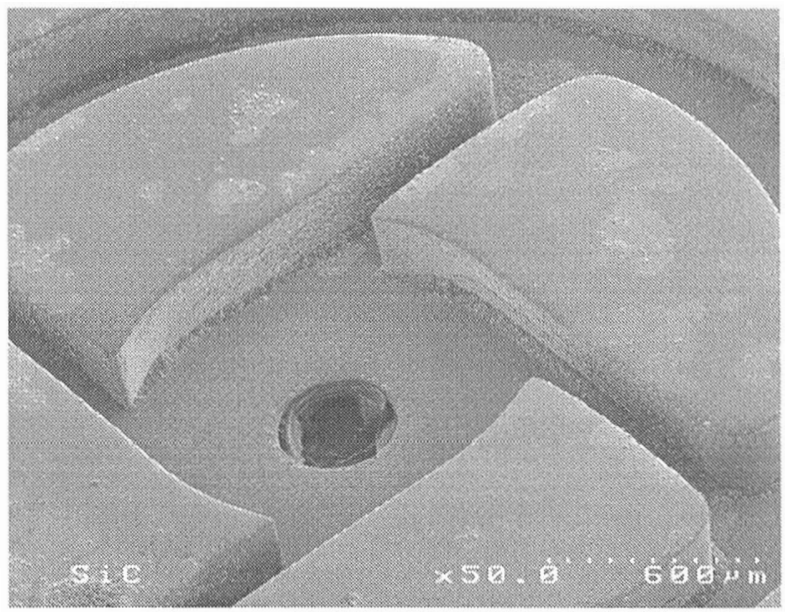

Fig. 4: SEM photo of a SiC atomizer. 


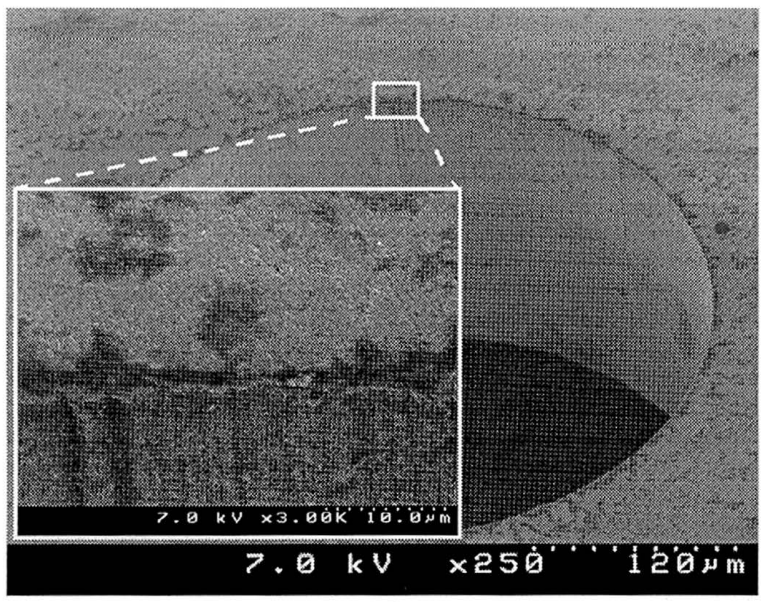

(a)

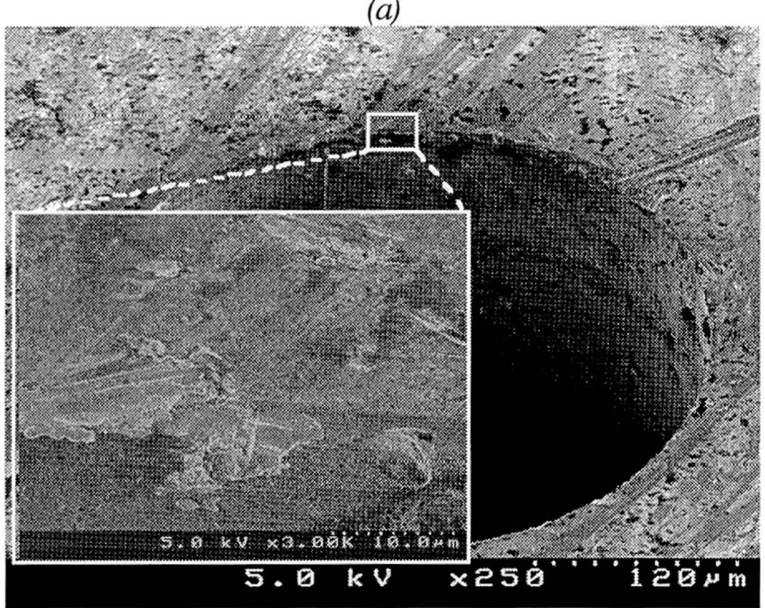

(b)

Fig. 5: SEM photos of the Ni atomizer exit orifice edge with close-up inlays: (a) Before the erosion test; and (b) after the erosion test.

\section{CONCLUSIONS}

SiC atomizers were successfully fabricated using a novel $\mathrm{Si}$ molding process and were compared with $\mathrm{Ni}$ atomizers fabricated using the MCNC LIGAMUMPs process. Both types of atomizers performed well at high pressures with the $\mathrm{SiC}$ devices exhibiting superior erosive wear resistance to $\mathrm{Ni}$, and both materials outperforming $\mathrm{Si}$. Performance tests demonstrated that both $\mathrm{SiC}$ and $\mathrm{Ni}$ atomizers exhibited similar flow performance to $\mathrm{Si}$ devices, with average flow rates of 9 and 7 PPH respectively at 660 $\mathrm{kPa}$, compared to $10 \mathrm{PPH}$ for the $\mathrm{Si}$ atomizers.

\section{ACKNOWLEDGMENTS}

The authors would like to acknowledge collaboration through the Aerospace MEMS Consortium (in part supported by DARPA), in particular Parker Hannifin Corporation for the use of their test facilities, and Dr. K. Stark at Advanced Micromachines Incorporated for the DRIE etching. The CWRU work was supported by a Multidisciplinary University Research Initiative from ARO (Contract Number DAAH04-10097).

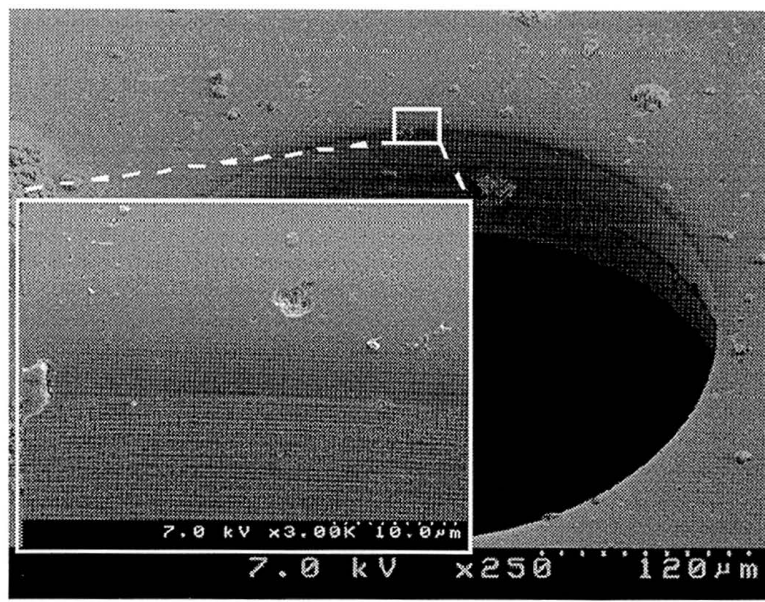

(a)

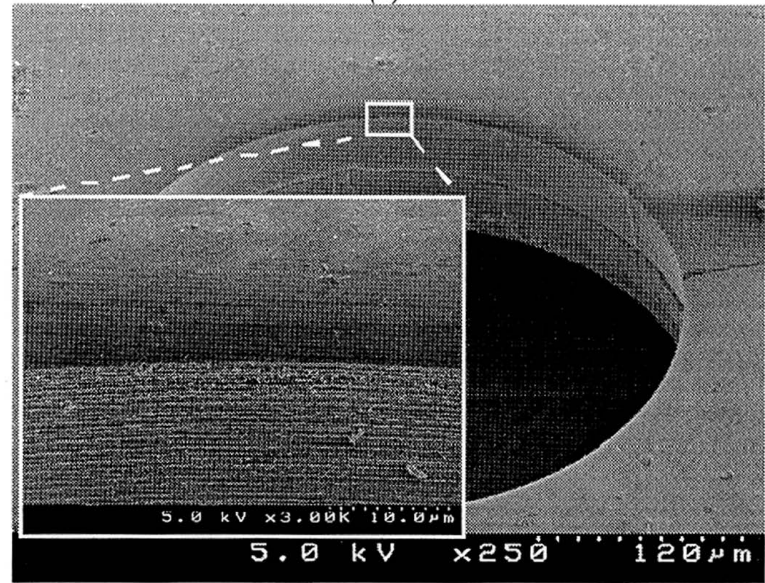

(b)

Fig. 6: SEM photos of the SiC atomizer exit orifice edge with close-up inlays: (a) Before the erosion test; and (b) after the erosion test.

\section{REFERENCES}

1. N. Rajan, C.A. Zorman, M. Mehregany, R. DeAnna, and R. J. Harvey, "Effect of MEMS-Compatible Thin-Film Hard Coatings on the Erosion Resistance of Silicon Micromachined Fuel Atomizers", Int'l Conf. on Metallurgical Coatings and Thin Films, San Diego, CA, (April 1998).

2. R. J. Harvey, "Progress on Comparison Study of the Erosion of Conventionally Machined and Macrolaminated PressureSwirl Atomizers", Int'l Gas Turbine and Aeroengine Congress and Exhibition, (1997).

3. A. Fleischman, S. Roy, C.A. Zorman, M. Mehregany, and L.G. Matus, "Polycrystalline Silicon Carbide for Surface Micromachining", 9th Annual Workshop on Microelectromechanical Systems, San Diego, CA, (Feb. 1996).

4. C.C. Chiu, S. B. Desu, G. Vhen, C.Y. Tsai, and W.T. Reynolds, Jr., "Deposition of Epitaxial $\beta$-SiC Films on Porous (100) from MTS in a Hot Wall LPCVD Reactor", J. Mater. Res., 10, 1099, (1995). 